\title{
CNG-Diesel Dual Fuel Controlling Concept for Common Rail Diesel
}

\section{Muammar Mukhsin Ismail", Mas Fawzi, Fathul Hakim Zulkifli, Shahrul Azmir Osman}

Automotive Research Group, Centre for Energy and Industrial Environment Studies (CEIES), Universiti Tun Hussein Onn Malaysia, Johor 86400, MALAYSIA.

Received 7 January 2018; accepted 23 January 2018, available online 3 July 2018

\begin{abstract}
Compressed Natural Gas (CNG) is gaining interest as a clean fossil fuel alternative in a diesel dual fuel system. The dual fuel system is proven to provide benefits in terms of fuel consumption and exhaust emission. This article briefly describes a concept of controlling strategy of a CNG-diesel dual fuel system for a common rail diesel engine. A lower diesel common rail pressure was emulated to reduce the diesel fuel quantity, then substitute it with an equivalent $\mathrm{CNG}$ fuel quantity. The tuning process is vital to ensure a comparable performance. It requires measurement of lambda values and tuning of both diesel and CNG set values in their respective look-up tables for the whole engine operation. Test results showed that the lambda values are between 1.5 and 3.0, depending on the load demand indicated by the accelerator pedal positions. This concept is relatively easy to be implemented, but it may cause poor combustion and emission quality due to poor diesel fuel atomization at lower injection pressure. However, an optimum performance and emission could be achieved by scrutinizing the diesel fuel reduction and CNG fuel substitution.
\end{abstract}

Keywords: Alternative fuel, CNG-diesel, dual fuel, common rail engine

\section{Introduction}

Compressed Natural Gas (CNG), which made up primarily of Methane $\left(\mathrm{CH}_{4}\right)$ is among the favorite for fossil fuel alternatives. Its favorable chemical properties are high hydrogen to carbon ratio $(\mathrm{H} / \mathrm{C})$ and high Research Octane Number (RON) compared to other fossil fuels [1]. In addition, CNG might offer a $20 \%$ reduction in greenhouse gas emission compared to gasoline and diesel [2]. Previous studies on CNG as alternative fuels, confirmed a gain in economic fuel consumption [3]. The operational cost using $\mathrm{CNG}$ is relatively lower, at one third of that vehicles running on gasoline, and half of that for vehicles running on diesel [4].

Conventional utilization of CNG with diesel engines comprises of three concepts: (i) dual fuel concept (mixture of $\alpha \%$ diesel and $\beta \% \mathrm{CNG}$ ), (ii) bi-fuel concept (alternate usage between 100\% diesel and 100\% CNG), and (iii) mono-fuel (100\% CNG). Based on established researchers on the conversion of the diesel engines, the dual fuel concept has an outright advantage of the most economical modification works over the other two [5]. The so-called diesel dual fuel (DDF) system uses CNG as the main fuel. The CNG is premixed with air and injected via intake manifold during induction and compression stroke. A small amount of diesel fuel will be directly injected as a pilot to initiate the combustion by compression ignition.

Most of the diesel engines available in the market can be converted to a DDF system, but according to Stalhammer et al. [6], diesel engine with common rail injection system is the most suitable for DDF application. The common rail system has the flexibility to control the diesel injection timing and quantity in order to increase the overall efficiency while optimizing the diesel substitutions demands for DDF systems.

There are many conversion kits for DDF system available commercially. Most of the kits were designed for any standard common rail diesel engine. Such system must work with the original equipment manufacturer (OEM) diesel engine without tampering the engine original settings. Currently, there are a few literatures that addressed the combustion and emission characteristic using these kind of kits [5]-[9]. Yang et al. [8] claimed to have developed an electronic gas control unit (EGCU) acting as a piggyback system for the original engine control unit (ECU). On the other hand, Wannatong et al. [9] worked on a DDF ECU acting as a replacement for the OEM ECU. Nonetheless, publications regarding to the controlling concept DDF system for common rail diesel engine are scarce, probably to trade secrets or intellectual property protections.

This article briefly describes a concept of controlling and managing strategies of a CNG-diesel DDF system for a common rail diesel engine; discussing its advantages and challenges.

\section{Hardware Setup}

Fig. 1 shows an installation diagram for the dual fuel conversion kit according to the author's previous study [10]. Hardware for the DDF system conversion mainly 
consists of an EGCU, a pressure gas regulator/reducer, several gas injectors, a dual fuel switch and a wire harness. For the hardware installation, CNG storage cylinders, valves, high pressure steel pipes and rubber hoses are also required. These high pressure hardware installations must meet the international standard and regulation, stipulated by the American National Standards Institute for Natural Gas Vehicle (ANSI NGV 2-2007) for safety reasons. Other accessories may often differ according to the OEM, and sometimes offer additional features such as information monitoring, knock detection and etc.

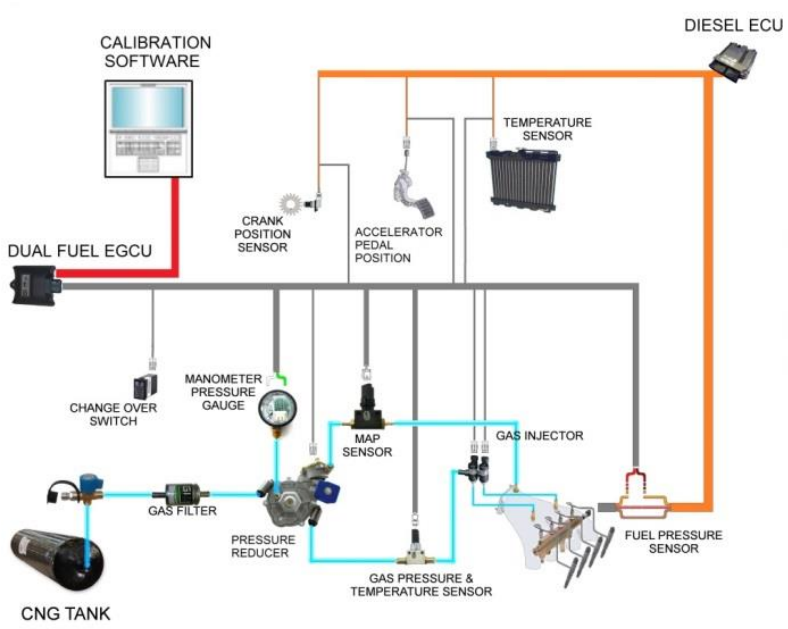

Fig. 1 Installation setup of a dual fuel conversion kit.

A control setup for the dual fuel operation is illustrated in Fig. 2. Based on Fig. 1 and Fig. 2, the dual fuel EGCU requires signals from the crank position sensor, accelerator pedal position (APP) sensor and common rail sensor in order to operate in dual fuel mode. All these signals that originally fed into the diesel ECU will remain untampered except for the common rail signal as it will be emulated by the dual fuel EGCU. The dual fuel EGCU controlled the diesel fuel quantity by emulating common rail pressure signal that originally fed into diesel ECU and set the injection duration for gas injector. During the dual fuel mode operation, the diesel injector shall be controlled by the diesel ECU while the gas injector will be controlled by the dual fuel EGCU.

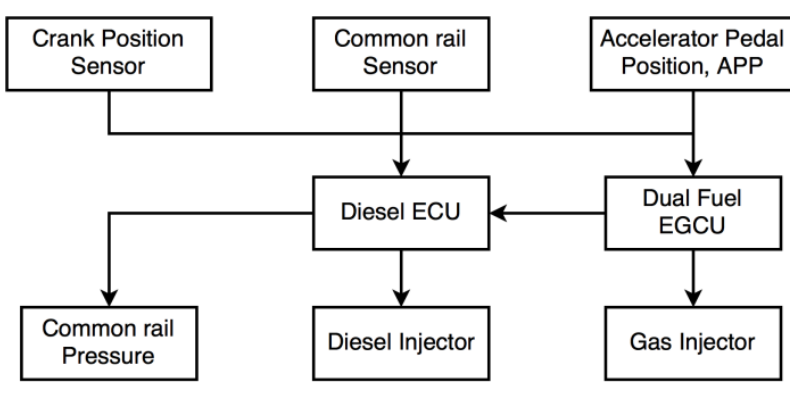

Fig. 2 Dual fuel mode control setup.

\section{Controlling Strategies}

\subsection{Dual Fuel Operation}

Before the start of any dual fuel system operation, the EGCU must be initialized by calibrating the common rail pressure, $\mathrm{P}_{\mathrm{CR}}$. As shown in Fig. 3, the voltage of the APP at $0 \%$ and $100 \%$ must firstly be determined. Then the engine speed must be calibrated and recorded. The voltages that correspond to the common rail pressure, $\mathrm{P}_{\mathrm{CR}}$ at idle and at $3000 \mathrm{rpm}$ must be measured and linear relationship between them must be established to enable proper emulation of the pressure signal. The range between idling and $3000 \mathrm{rpm}$ was arbitrarily chosen based on typical diesel engine operating condition, whereby the maximum engine torque is normally found at $2500 \mathrm{rpm}$.

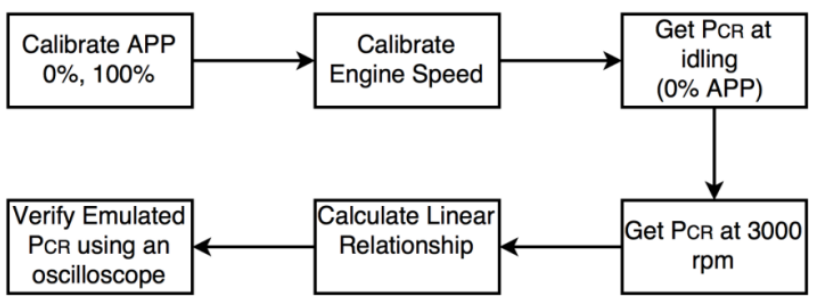

Fig. 3 EGCU calibration for common rail pressure emulation.

Fig. 4 shows a relationship between common rail pressure and the APP of a Toyota 4-cylinder 2.5L diesel engine. These values were measured using Bosch Diagnostic Tools KTS-570 while the engine is attached to a chassis dynamometer. The test was performed at constant engine speeds of 1000, 1500, 2000, 2500, 3000 and $3500 \mathrm{rpm}$, with full load exerted by the dynamometer.

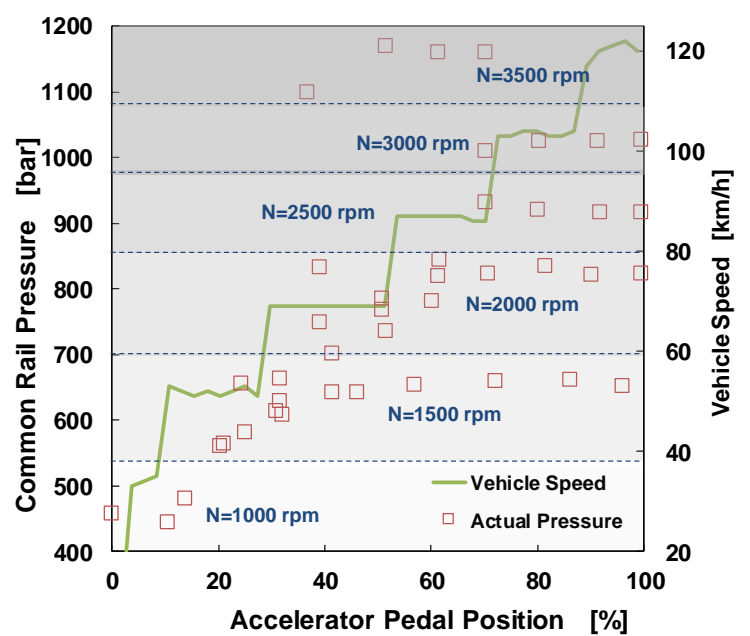

Fig. 4 Relationship between common rail pressure, vehicle speed, engine speed with respect to accelerator pedal position.

During such exercise, vehicle speeds were recorded along with the diesel common rail pressure. The 
secondary vertical axis in the same figure show the vehicle speed with respect to the APP. The scale of both vertical axes is not similar, but somewhat arbitrarily chosen so that both data corresponded to each other in the relation of engine speed, $\mathrm{N}$. The figure represents overall diesel engine behaviour. It can be noticed that the common rail pressures remain approximately the same at a particular engine speed, although the APP changed.

From the figure, when the vehicle speed is around $100 \mathrm{~km} / \mathrm{h}$ (simulating highway cruising) with the engine running at $3000 \mathrm{rpm}$, the common rail pressures remain approximately at 1000 bar although APP changed between $70-100 \%$. On the other hand, at $55 \mathrm{~km} / \mathrm{h}$ (simulating town driving) with the engine running at 1500 $\mathrm{rpm}$, the common rail pressures fluctuated between 600700 bar while APP changed between 20-100\%.

During the dual fuel running mode, each engine control cycle has an additional process as shown in Fig. 5. For each cycle, after the APP and the engine speed signals were read, CNG and diesel set values (Fig. 6 and Fig. 7) will be referred to for both fuel injections for any operating condition. Then, the CNG injection signal shall be produced and simultaneously common rail pressure shall be emulated in order to reduce the diesel fuel injection quantity.

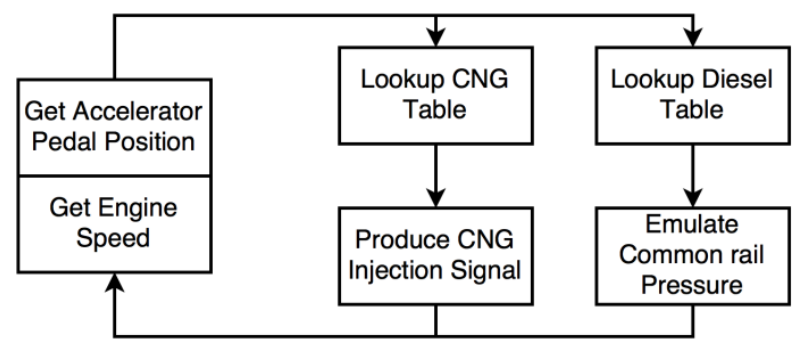

Fig. 5 DDF mode cyclic process.

\subsection{Reducing Diesel Fuel Quantity}

During the dual fuel mode, a portion of the diesel fuel needs to be reduced then replaced with CNG. In order to do so, signal from the common rail pressure sensor that was fed into the diesel ECU was cut off and fed into the dual fuel EGCU. The EGCU reads the lookup table for any diesel injection operating condition. Then the EGCU produces a continuous emulated common rail pressure signal to be fed into the diesel engine ECU. Fig. 6 and Fig. 7 show the diesel and CNG set value lookup table respectively. Both tables contain set values that correspond to any accelerator pedal position (y-axis) and engine speed ( $\mathrm{x}$-axis).

The set values in the diesel table are not absolute. It does not give the values of the common rail pressure in term of any pressure unit throughout the engine operating map. Rather, the set values in the diesel table were entered as any integer values between 100 and 300. These values act as a multiplier for the emulated common rail pressure. Such values also do not represent exact fuel quantity. To get the emulated common rail pressure values, the following formulas were used.
$\mathrm{P}_{\mathrm{CR} \_ \text {emulated }}=\mathrm{P}_{\mathrm{CR}} \mathrm{x}$ set_value $/ 100$

$\mathrm{P}_{\mathrm{CR} \_ \text {actual }}=\mathrm{P}_{\mathrm{CR}} \times 100 /$ set_value

Where $\mathrm{P}_{\mathrm{CR}}$ is the common rail pressure, set_value is the value set by the tuner in the diesel lookup table, $\mathrm{P}_{\mathrm{CR} \_ \text {emulated }}$ is the emulated common rail pressure, and $\mathrm{P}_{\mathrm{CR} \_ \text {actual }}$ is the common rail pressure after the engine ECU adjustment. The mechanism applied for such strategy so that; if the required diesel quantity need to be cut in half, the emulated common rail pressure signal should be nearly double then that the original common rail. The original diesel ECU then will think that the pressure in the common rail is too high for the desired operation, thus the diesel ECU will cut the actual pressure into lower pressure. Lowering the fuel injection pressure means reducing the diesel fuel quantity.

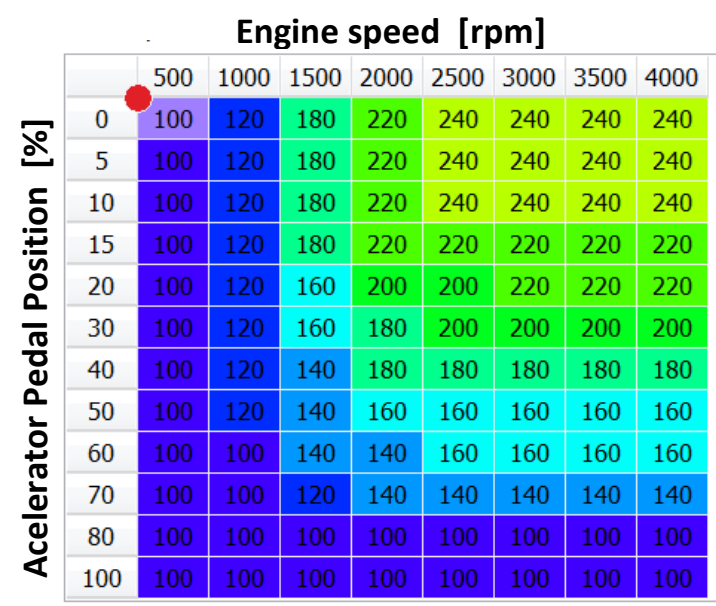

Fig. 6 Diesel set value lookup table.

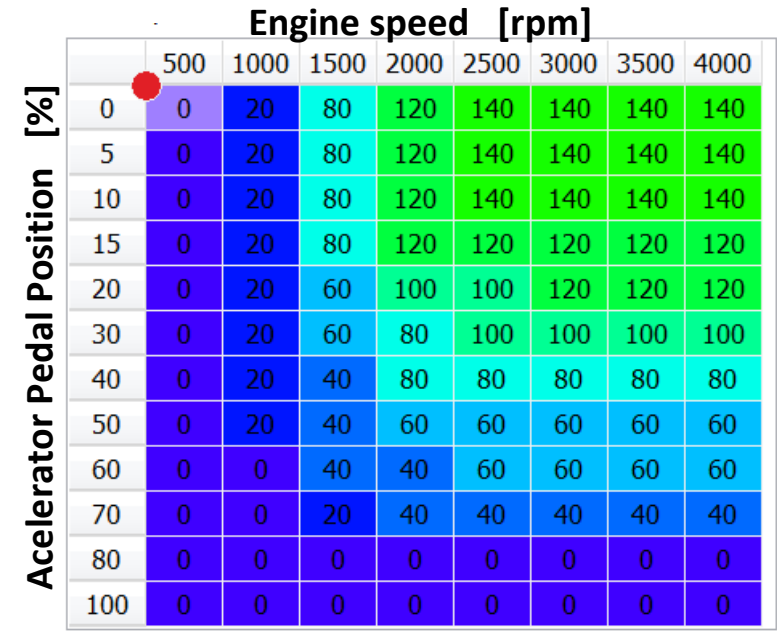

Fig. 7 CNG set value lookup table.

\subsection{Adding $C N G$}

Slightly different from the diesel table, the set value of the CNG table has an integer range between 0 and 255 , where such values shall produce the duty cycle of $0 \%$ and $100 \%$ respectively. These set values, are not giving the 
CNG absolute injection duration and quantity suitable for any engine type and model. Instead, those set values are used as a reference, taking into consideration the number of gas injector installed and their static flow rate.

\subsection{Ensuring Equivalence Performance}

Reducing the diesel fuel quantity means changing the air fuel ratio. Following the $\mathrm{CNG}$ substitutions, the original air fuel ratio during the diesel mode must be sustained to ensure similar engine performance for both the normal diesel mode and the dual fuel mode. In order to achieve that, lambda values from the engine idling condition to $3500 \mathrm{rpm}$ were measured with respect to APP as illustrated in Fig. 8. From the figure, it shows that the diesel engine was set to run with lean mixtures during low loads (APP < 50\%) and running rich mixtures at high loads (APP > 50\%). For example, at high loads with APP values at $60-100 \%$, the engine runs with rich fuel-air mixture, approximately at 1.5 lambda value.

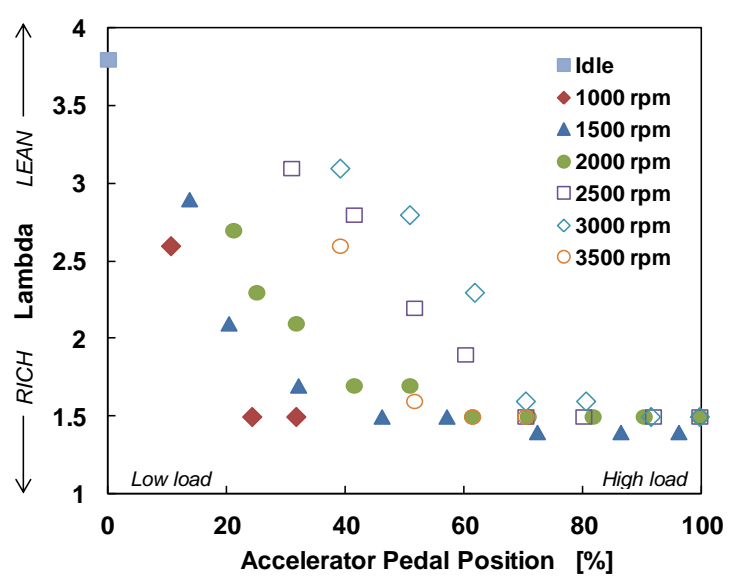

Fig. 8 Measured lambda values.

Using this concept, the lambda value was considered as a reference to ensure an equivalence performance between diesel and dual fuel operation. The reduction of diesel fuel and substitution of CNG fuel needs to be done by adjusting the lambda value close to the original value. The lambda measured for the diesel fuel mode at high load were mostly near 1.5 . Therefore, the lambda value for dual fuel operation need to be in this range.

Based on the measured lambda values, calibrations of the lookup tables for the engine operation map (Fig. 6 and Fig. 7) are required to ensure equivalence performance during the running of the dual fuel mode. For example, at $2500 \mathrm{rpm}$ and $60 \%$ APP, the measured lambda value during the diesel mode is 1.9. The ratio based on CNG-diesel lookup table is 60:160. If the lambda value on that condition changed, let say more than 1.9 (leaner mixtures), means the set value for $\mathrm{CNG}$ need to be increased until it reaches the original lambda value. The tuning process can be quite extensive because it requires measurements of lambda values and setting both diesel and $\mathrm{CNG}$ set values throughout the $8 \times 8$ look-up table that represent the whole engine operation.

In some cases, during the tuning of the DDF system, the 'check engine' of the vehicle may appear due to any sudden change in lambda values. What may happen is that the diesel ECU thinks that there might be a fuel leak and could be hazardous to the vehicle driver and passengers. Knowing this, such 'check engine' light can be turned off by restarting the engine or by deleting the error code using any engine scan tool. If the $\mathrm{CNG}$ is added too much, the air-fuel ratio become rich mixtures and increases engine performance, but at the same time increases the overall fuel consumption.

There is no specific rule in mixing strategies between CNG and diesel fuels. According to Thipse et. al., typical diesel replacement strategy in dual fuel mode is no diesel replacement at low loads, 30-75\% at normal operating condition and $40 \%$ at high loads [7]. Based on the authors' experience, the recommended mixing strategy is to run with $100 \%$ diesel mode at idle and high loads, while running with the dual fuel mode at other driving conditions to ensure equivalence engine performance and optimum fuel economy.

\section{Discussion}

\subsection{Advantages}

Controlling the fuel quantity by reducing the fuel pressure is a relatively simple strategy for the dual fuel operation. The modification work for the initial conversion of any diesel engine into the dual fuel system requires minimum installation of additional components. In terms of calibration, the tuning process is relatively easy and requires no special skill by the tuner. The dual fuel system is interchangeable with diesel mode, which is very useful in certain area where CNG supply is not available. In fact, this dual fuel system is suitable for most common rail diesel engine available in the market. This controlling concept would be a robust system; which means it is highly suitable for other types of diesel engines.

\subsection{Challenges}

In contrast, lowering the common rail pressure would means lowering the diesel fuel injection pressure. Lowering the injection pressure may achieve the desired outcome of reducing the diesel fuel quantity, but may result in other problems [11]. It is known that low diesel injection pressure will produce larger Sauter Mean Diameter (SMD) fuel droplets. SMD is defined as the mean of volume over the mean of surface area. It is generally accepted measures to judge the mean size of fuel droplets against combustion quality. According to the following empirical finding by Hiroyosu and Kadota, the reduction of injection pressure result in the increase of droplet SMD [12].

$$
S M D=2330 \rho_{A}{ }^{0.121} Q^{0.131} \Delta P_{L}^{-0.135}
$$

Where $\rho_{A}$ is the air density $\left(\mathrm{kg} / \mathrm{m}^{3}\right), \mathrm{Q}$ is the amount of fuel delivery $\left(\mathrm{mm}^{3} /\right.$ stroke $)$, and $\Delta P_{L}$ is the effective pressure drop between fuel and air (MPa). Large droplet SMD retards the vaporization of the diesel fuel spray, and 
may cause combustion instability. Moreover, the emission quality also worsens with low injection pressure [13], [14] and [15].

Recent diesel engines commonly utilize multiple fuel injections per cycle strategy to augment combustion and to lower exhaust emissions. Each cycle diesel fuel injection is divided into several injection stages: advanced injections (before top dead centre, BTDC) and retarded injections (after top dead centre, ATDC). So, lowering fuel injection pressure may cause missed injection/firing as the fuel quantity may be too lean for any ignition to take place. In this case, the effect of reducing fuel injection pressure would be worst.

\section{Conclusion}

Through this dual fuel concept, the reduction of diesel fuel quantity can be done by reducing common rail pressure and substituted by CNG fuel. In order to ensure an equivalence performance, the lambda value during the dual fuel mode needs to be benchmarked with the original diesel mode, which has lambda values between 1.5 and 3.0, depending on the load demand indicated by the accelerator pedal positions. Although this concept is relatively easy to be implemented, it may cause combustion and emission problems. The diesel fuel quantity could be reduced, but it would suffer in terms of combustion and emission quality. The reduction of diesel fuel pressure increasing the droplet SMD and resulting the poor atomization of diesel fuel spray. However, this concept may give an optimum dual fuel performance if the reduction is done carefully.

\section{References}

[1] R. H. Madon, M. Fawzi, S. A. Osman, A. J. Alimin, A. Razali, M. Khairul, I. Sarwani, and Z. Z. Abeden, Gas Chromatography Analysis of a C1-C5 Hydrocarbon Column, Int. J. Integr. Eng., vol. 10, no. 1, pp. 85-91, 2018.

[2] F. Konigsson, Advancing the Limits of Dual Fuel Combustion, Royal Institute of Technology, 2012.

[3] M. Fawzi Mohd Ali, Y. Kodoguchi, Y. Oka, and T. Kaida, Improvement of Combustion of CNG Engine using CNG Direct Injection and Gas-jet Ignition Method, in SAE Paper, 2011, no. 201101-1994, pp. 1863-1872.

[4] Semin and R. A. Bakar, A Technical Review of Compressed Natural Gas as an Alternative Fuel for Internal Combustion Engines, Am. J. Eng. Appl. Sci. Eng. Appl. Sci., vol. 1, no. 4, pp. 302-
311, 2008.

[5] M. C. Besch, J. Israel, A. Thiruvengadam, H. Kappanna, and D. Carder, Emissions Characterization from Different Technology Heavy-Duty Engines Retrofitted for CNG/Diesel Dual-Fuel Operation, SAE Int. J. Engines, vol. 8, no. 3, pp. 2015-01-1085, Apr. 2015.

[6] P. Stalhammar, L. Erlandsson, and K. Willner, Report SGC233: Assessment of Dual-Fuel Technology, 2011.

[7] S. Thipse, A. V. Kulkarni, S. J Vispute, S. D. Rairikar, S. B. Sonawane, V. S. Sagare, S. Dev, K. K. Kavathekar, P. Mengaji, U. Shailesh Karle, N. V Marathe, and K. Sinha, Development of Dual Fuel (Diesel-CNG) Engine for SUV Application in India, Jan. 2015.

[8] B. Yang, X. Wei, K. Zeng, and M.-C. Lai, "The Development of an Electronic Control Unit for a High Pressure Common Rail Diesel/Natural Gas Dual-Fuel Engine, 2014.

[9] K. Wannatong, S. Kongviwattanakul, T. Tepimonrat, and T. Priroon, Development of Hardware in the Loop System Implemented for Engine Control Unit End of Line Test, 2014.

[10] M. M. Ismail, H. Zulkifli, M. Fawzi, and S. A. Osman, Conversion Method of a Diesel Engine to a CNG-Diesel Dual Fuel Engine and its Financial Savings, ARPN J. Eng. Appl. Sci., vol. 11, no. 8, 2016.

[11] A. R. Andsaler, A. Khalid, and N. Jaat, Simulation and Modeling of Mixture Formation under Variant Ambient Condition and Injection Pressure of Biodiesel Spray, Int. J. Integr. Eng., vol. 9, no. 3, pp. 18-23, 2017.

[12] H. Hiroyasu and T. Kadota, "Fuel Droplet Size Distribution in Diesel Combustion Chamber," 1974.

[13] J. Liu, A. Yao, and C. Yao, Effects of diesel injection pressure on the performance and emissions of a HD common-rail diesel engine fueled with diesel/methanol dual fuel, Fuel, 2015.

[14] H. T, Effect of Injection Pressure on Performance of Dual Fuel Diesel Engine, 2013.

[15] K. Ryu, "Effects of pilot injection pressure on the combustion and emissions characteristics in a diesel engine using biodiesel-CNG dual fuel," Energy Convers. Manag., vol. 76, pp. 506-516, 2013. 